\title{
Eye care utilisation patterns in a rural county in Ireland: implications for service delivery
}

\author{
Colleen Clendenin, Michele Coffey, Marta Marsh, Sheila West
}

\begin{abstract}
Aims/background-This investigation determined eye care utilisation patterns in a rural county in Ireland. Population based estimates of visual impairment and glaucoma were available, so the two studies will optimise planning for eye care services for the county.

Methods-Roscommon has a population of 55000 served by one ophthalmologist and two optometrists. Data were collected on all outpatient visits for all providers for a 3 month period. Information was abstracted on demographics, presenting and final diagnoses. Expected number of visits for glaucoma were calculated using the population structure and rates of glaucoma, and assuming one visit per year per glaucoma patient.

Results-1398 patients had a total of 1442 visits in 3 months. A third of the visits were to optometrists, and all but 21 visits were for normal eye examinations or glasses. The majority of children aged less than 16 years, and people older than 60 years were seen by the ophthalmologist. Among children, $81 \%$ of all visits were to the ophthalmologist and $92 \%$ were classified as a normal examination. Only an estimated 188 visits per year for glaucoma were observed, compared with 1100 expected.
\end{abstract}

Conclusion-In this rural county, many of the visits to the ophthalmologist were for normal eye examination, particularly among children. Screening algorithms which would free the ophthalmologist to see more complicated problems could be considered. There is an underutilisation of services by glaucoma patients. Reasons for this are described.

(Br F Ophthalmol 1997;81:972-975)

A population based survey of blindness and visual impairment was carried out between 1988 and 1990, in Roscommon County, Ireland. ${ }^{1}$ The goal of that study was to determine the prevalence of glaucoma and other conditions within the county in order to improve the planning of eye care services within Roscommon as well as other, similar communities. The survey found that the prevalence of blindness was $0.5 \%$, low vision was $2.1 \%$, and the prevalence of glaucoma was $1.9 \%$ in Roscommon.

Glaucoma rates were among the highest reported from other surveys among white populations which vary from $0.4 \%$ to $2.1 \%$ in the age group 40 years and older. ${ }^{2-8}$ This suggests the importance of this disease in this county (for a review of the prevalence of glaucoma, see Javitt and Chiang ${ }^{9}$ ).

These population based data led to another series of questions on existing eye care utilisation patterns in the county, and how the patterns might change to optimise service. By combining the population based data on glaucoma from the earlier survey with utilisation rates in this current study, it is possible to determine utilisation patterns of eye care for this rural county.

\section{Methods}

In 1977, a document was produced by the Irish Faculty of Ophthalmology recommending the development of community ophthalmic services. By August 1991, all community ophthalmologists could become permanent community care employees as existing positions become vacant. Most had been in the community since the early 1980 s. At present, there are 57 community ophthalmologists in clinical practice in southern Ireland. All have diplomas in ophthalmology, reflecting 3 years in hospital ophthalmic posts.

Roscommon County is a rural county located in the west of Ireland. It has a population of approximately 55000 , which is served by one community ophthalmologist and two optometrists, responsible for outpatient eye services. The ophthalmologist has both a public and private practice. Her public practice consists of clinics held in towns throughout the county on a weekly or biweekly basis. Both optometrist practices are private. In Ireland, examinations and refractions are free for those aged 16 and under, and subsidised for those aged 60 and older. Public practices serve these age groups, as well as those who are certified as unable to pay.

Data were collected from all outpatient visit records for patients seen by an ophthalmologist or optometrist in County Roscommon, Ireland, between the dates of 1 July 1994 and 30 September 1994. Information was abstracted for each visit from the medical records regarding demographics and clinical information. There was a total of 1398 patients with 1442 visits during that time. Information recorded included the following - age in years at time of visit, sex, residence (town), date of visit, origin of visit (that is, referral by another provider, self referred, new, or follow up visit), date of referral, reason for referral, if noted, suspected reason for visit, procedures performed, medica-
Accepted for publication 28 May 1997 
Table 1 Age distribution of 1442 visits by provider type (\%) in Roscommon County

\begin{tabular}{llllll}
\hline Age (years) & Number of visits * & $\begin{array}{l}\text { Ophthalmologist } \\
\text { (private) }\end{array}$ & $\begin{array}{l}\text { Ophthalmologist } \\
\text { (clinic) }\end{array}$ & Optometrist & Total \\
\hline$<5$ & 79 & 16 & 84 & 0 & 100 \\
$5-16$ & 285 & 13 & 68 & 19 & 100 \\
$17-29$ & 126 & 52 & 8 & 40 & 100 \\
$30-39$ & 61 & 44 & 10 & 46 & 100 \\
$40-49$ & 92 & 45 & 20 & 35 & 100 \\
$50-59$ & 104 & 37 & 10 & 53 & 100 \\
$60-69$ & 149 & 36 & 29 & 35 & 100 \\
$70-79$ & 215 & 29 & 43 & 28 & 100 \\
\hline
\end{tabular}

$\star 221$ visits were from patients who did not have ages recorded in the chart.

tions or glasses prescribed, final diagnosis, and disposition.

Each provider maintained their records in a different manner. The public ophthalmology practice and one of the optometrists maintained a $\log$ book which recorded the name of each patient seen on a given day, and then a separate file for each patient with records of each visit. The private ophthalmology practice recorded all information in log books in the chronological order in which patients were seen. The second optometrist no longer had a $\log$ of the patients seen during the previous year, so each patient's file had to be examined to see if they had been seen during the study period. Each record had been written by the eye care provider who had examined that patient.

For the purposes of this study, the origin of the visit was considered to be a referral if the chart contained a referral letter, or if the written history states that the patient is being seen as a referral. A patient was considered self referred if it was the patient's first visit for the current concern, and the patient was not referred by another healthcare provider. If the patient had been seen previously by the same doctor for a related problem then it was considered a follow up visit.

A patient was considered a resident of Roscommon if the recorded town of residence was in Roscommon County. All visits to eye care providers within the county were counted for analyses, regardless of the residency, assuming that the number who came into the county for eye care $(19 \%)$ was similar to the number of Roscommon residents who went outside of the county to receive their eye care. Since we had no way of assessing services obtained outside the county by county residents, this assumption will inflate our estimates of visits if, in fact, services are not sought outside the county.

All data were entered into customised PARADOX programs, and were analysed using sAs. Data were grouped by age, sex, and provider, and differences tested using $\chi^{2}$ tests. To deter-

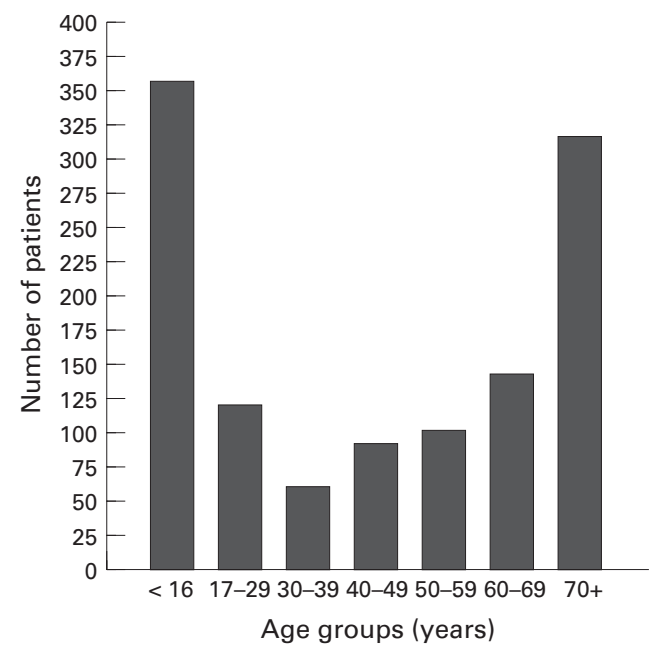

Figure 1 Age distribution of 1398 patients seeking eye care in Roscommon County.

mine the expected number of visits for glaucoma, we took the estimated number of glaucoma patients identified from the original survey in Roscommon ${ }^{1}$ and presumed one visit a year would be conservative. This number was compared with the actual number of visits mentioning glaucoma, high intraocular pressure, or ocular hypertension, or visits in which medicine for glaucoma was prescribed.

\section{Results}

Data were collected on all 1398 patients, who had a total of 1442 visits within 3 months. Of the 1398,569 were male and 829 were female. A total of $81 \%$ were Roscommon residents (1131 of 1398). The ages of the patients seen over the 3 months approximated a 'U shaped' distribution, with more patients either under 16 years of age, or over 70 years old, than any other age (see Fig 1).

Of the total visits, $38 \%$ were seen in the public ophthalmologist practice (546 visits), 29\% were seen in the private ophthalmologist practice (420 visits), and the remaining 33\% were seen by optometrists (476 visits). There was little difference in distribution of visits by sex of the patient between the three types of practices $\left(\chi^{2}=4.41, \mathrm{p}=0.11\right)$. The age distribution, however, varied greatly between different provider types $\left(\chi^{2}=318, \mathrm{p}<0.001\right)$. Table 1 shows the number of each age grouping that was seen by each of the sources of care, for a total of $100 \%$ for each age category. The ophthalmologist's public practice accounted for the majority $(71 \%)$ of children less than 16 years old who were seen, but less than $20 \%$ of

Table 2 Age distribution of reason for visit by provider type

\begin{tabular}{|c|c|c|c|c|c|c|}
\hline \multirow[b]{2}{*}{ Diagnosis } & \multicolumn{2}{|l|}{$\geqslant 16$ years } & \multicolumn{2}{|l|}{$17-49$ years } & \multicolumn{2}{|l|}{$50+$ years } \\
\hline & Ophthalmologist & Optician & Ophthalmologist & Optician & Ophthalmologist & Optician \\
\hline Chronic eye disease & 37 & 1 & 10 & 0 & 99 & 1 \\
\hline Squint & 18 & 0 & 0 & 0 & 0 & 0 \\
\hline Normal eye exam/glasses & 200 & 47 & 88 & 103 & 178 & 182 \\
\hline Acute trauma, VA loss & 22 & 1 & 5 & 0 & 25 & 0 \\
\hline Other & 33 & 5 & 66 & 7 & 87 & 6 \\
\hline
\end{tabular}


Table 3 Distribution of final diagnosis by provider for patients age $\leqslant 16$ years who came for a normal eye examination

\begin{tabular}{|c|c|c|c|c|c|c|}
\hline \multirow[b]{2}{*}{ Final diagnosis } & \multicolumn{2}{|c|}{$\begin{array}{l}\text { Ophthalomolist } \\
\text { (clinic) }(n=174)\end{array}$} & \multicolumn{2}{|c|}{$\begin{array}{l}\text { Ophthalmologist } \\
\text { (private) }(n=26)\end{array}$} & \multicolumn{2}{|c|}{$\begin{array}{l}\text { Optician } \\
(n=47)\end{array}$} \\
\hline & $n$ & $\%$ & $n$ & $\%$ & $n$ & $\%$ \\
\hline Myopia/hyperopia normal & 162 & 93 & 22 & 84 & 47 & 100 \\
\hline Amblyopia/strabismus & 7 & 4 & 2 & 8 & 0 & 0 \\
\hline Other & 5 & 3 & 2 & 8 & 0 & 0 \\
\hline
\end{tabular}

visits by each group from 17 to 59 . Older individuals were also more likely to be seen in the clinic with an increase by age, beyond age 60 .

The initial reason for visit was examined by age and by provider type (Table 2). Most of the visits where the presenting reasons were chronic eye diseases, squint, acute trauma, and visual acuity loss were seen by the ophthalmologist. For squint, this was not surprising since young children with a positive family history are referred by public health providers for cycloplegic refraction by an ophthalmologist. All but 21 of the visits to the optometrist were for a normal eye exam or for glasses. The ophthalmologist also had a large majority of visits classified initially as normal eye examinations (Table 2). This was most notable in the age group under 16 , where 200 visits occurred for normal examinations in the 3 month period.

Further exploration of the final diagnoses for the normal examinations was carried out for the age group 16 and under. Of the 247 visits for a normal examination in this age group, between $3 \%$ and $8 \%$ had a final diagnosis of amblyopia, strabismus, or other, all diagnosed by the ophthalmologist (Table 3). A total of $81 \%$ of all visits in this age group were to the ophthalmologist, with $92 \%$ resulting in a normal examination or patients needing glasses only.

According to the original Roscommon survey, approximately 1100 county residents have glaucoma, ${ }^{1}$ so we expected approximately 1100 visits in a year for glaucoma, ocular hypertension, or pressure check. However, based on the 3 month experience, only an estimated 188 yearly visits were observed, or $17 \%$ of what was expected. There was no seasonality reported in visits for glaucoma that might explain the low estimate.

\section{Discussion}

During the 3 month period of observation, a total of 1442 visits to the three eye care professionals in the county were made. Most of the visits, $67 \%$, were to the single ophthalmologist, either at her private or public practice. Many of the visits to the ophthalmologist were for a normal eye examination or glasses, particularly in the age group 16 and younger. Because only 3 months during the summer were sampled, an issue could be raised that these were not representative months. For example, farmers are particularly busy during summer months and were less likely to come in. The ophthalmologist recorded 966 visits during July to the end of September in this study, and recorded 824 visits the previous January to the end of March, a difference of 142 visits. If anything, the visit rate was higher during the summer period sampled. However, detailed data were not collected as part of this study in the kind of visit, or ages of patients, during the winter sampling period, so it is possible that different patterns of care might be observed in winter or spring months.

Similar data on eye care utilisation exist in the USA. For example, the National Ambulatory Medical Care Survey (NAMCS), conducted in 1990, determined the distribution and annual rate of outpatient ambulatory visits to ophthalmologists. ${ }^{9}$ For patients over 65 years old, there were an average of 740.2 visits per 1000 people (811.4 visits/1000 women and 645.0 visits/1000 men). In Roscommon, the average visit rate per 1000 for those 65 and older was 169 per 1000. The principal diagnoses among all ambulatory eye care visits in the USA were cataracts $(25.6 \%)$, disorders of refraction $(16.8 \%)$, and glaucoma $(16.3 \%)$. However, without population based data on prevalence of these conditions, it is difficult to determine the appropriateness of this rate, or the optimal number of visits.

Community ophthalmology service is relatively new, having been proposed in 1977 and implemented in 1991, in response to the growing demand for outpatient care. Based on these data, one might construct a more optimal distribution of visits among the trained staff, in which optometrists were working together with the ophthalmologist in the public practice to screen and see patients 16 and younger for a normal eye examination, thus freeing the ophthalmologist to see patients with chronic eye diseases or more complicated problems. The few patients found to have amblyopia, strabismus, or other problems could easily be referred, if necessary.

There is an underutilisation of eye care services by glaucoma patients in this county. Only an estimated $17 \%$ of glaucoma patients on average, were seen by an ophthalmologist each year. This underutilisation may have one of several possible explanations. Firstly, glaucoma is a silent disease and many people may be unsure that they have glaucoma. Of those found to have glaucoma in the Roscommon survey, an estimated $50 \%$ were unaware of their condition. If only those who were aware of their glaucoma came for a visit once a year, the estimated visit rate would be 550 , compared with 188 actually seen, or $34 \%$ of expected visits. Ideally, in Roscommon, glaucoma patients will be seen twice a year (once for a dilated examination and a second visit for another visual field test).

Another possible explanation for the low rate of visits for glaucoma may be that, although there is an awareness of glaucoma, patients do not utilise the care that is available to them. Underutilisation of services by patients with eye disease has been studied, primarily for cataract. Reasons for declining cataract surgery include fear, perception that cataract was not serious, problem getting assistance to the clinic, and perceived cost. ${ }^{10-12}$ Some glaucoma patients may also be seeking care outside the county; we did not measure the magnitude of outside care, but it probably does not explain 
much of the low utilisation of services by glaucoma patients. Glaucoma is managed by the community ophthalmology practice, and the ophthalmologist enjoys good rapport with the county residents. Poor public transport and expensive taxi service mitigate against seeking care much further away than Roscommon for most residents.

Javitt has suggested that lack of education about eye disease may contribute to the disparity between whites' and African-Americans' utilisation of services for glaucoma. ${ }^{13}$ Anecdotally, Coffey reports that understanding information on glaucoma is improved if there is an accompanying person at the visit. Any or all of these proposed reasons may contribute to the underutilisation of eye care service for glaucoma in Roscommon.

\section{Conclusion}

These data suggest further research into optimising eye care services for rural Ireland is indicated. Optimal distribution of visits among trained eye care staff might free the community ophthalmologists to concentrate on patients with chronic eye disease. Data on the low visit rate of glaucoma patients suggest that further investigation into reasons for utilisation of eye care services is warranted, so that steps can be made to better serve the region.

Supported by NIH Grant No EY01765 for Wilmer Biostatistical Center. The authors are grateful to the Western Health Board, Dr Colm A Hennigan, and Dr Brogan's optometrist office staff for opening their records and assisting in the data collection. This work was supported in part by the Roy $\mathrm{O}$ Scholz award to Ms Clendenin while a medical student. Dr West is a Research to Prevent Blindness, senior scientific investigator.

1 Coffey M, Reidy A, Wormald R, Xian WX, Wright L, Courtney P. Prevalence of glaucoma in the west of Ireland. Br f Ophthalmol 1993;77:17-21.

2 Leibowitz HM, Krueger DE, Maunder LR. The Framingham eye study. Surv Ophthalmol 1980;24:(suppl) 335-610.

3 Tielsch J, Sommer A, Katz J, Royall R, Quigley H, Javitt J. Racial variations in the prevalence of primary open angle glaucoma. FAMA 1991;226:369-74.

4 Vernon SA, Henry DJ, Cater L, Jones SJ. Screening for glaucoma in the community by non-ophthalmologically trained staff using semiautomated equipment. Eye 1990;4: 89-97.

5 Lindblom B, Thorborn W. Prevalence of visual field defects due to capsular and simple glaucoma in Halsingland, Sweden. Acta Ophthalmol 1982;60:353-61.

6 Dielmans I, Vingerling JR, Wolfs RCW, Hofman A, Grabbee $\mathrm{DE}$, de Jong $\mathrm{P}$. The prevalence of primary open-angle glaucoma in a population based study in the Netherlands. Ophthalmology 1994;101:1851-5.

7 Klein BEK, Klein R, Sponsel WE, Franke T, Cantor LB, Martone J, et al. The Beaver Dam eye study. Ophthalmology 1992;99:1499-504.

8 Tielsch JM. The epidemiology and control of open angle glaucoma: a population-based perspective. Annu Rev Public Health 1996;17:121-36.

9 Javitt JC, Chiang YP. Preparing for managed competition: utilization of ambulatory eye care visits to ophthalmologists. Arch Ophthalmol 1993;111:1034-5.

10 Gupta S, Murthy GVS. Where do persons with blindness caused by cataracts in rural areas of India seek treatment and why? Arch Ophthalmol 1995;113:1337-40.

11 Concha $M$. The natural history of senile cataract treatment in the Chilean Health System. Baltimore, MD: Doctoral Thesis, 1993.

12 Brilliant GE, Brilliant LB. Using social epidemiology to understand who stays blind and who gets operated for cataract in a rural setting. Soc Sci Med 1985;21:553-8.

13 Javitt JC. Preventing blindness in Americans: the need for eye health education. Surv Ophthalmol 1995;40:41-4. 